\title{
De árvore invasora à matéria-prima - pesquisa sobre o potencial de uso da leucena para o design de produtos
}

\section{From invasive tree to raw material - a research on the potential use of leucena wood for product design}

\author{
Clara de Souza Bartholomeu, Faculdade de Arquitetura e Urbanismo - USP \\ bartholomeuclara@gmail.com \\ Cyntia Santos Malaguti de Sousa, Faculdade de Arquitetura e Urbanismo - USP \\ cyntiamalaguti@usp.br
}

\author{
Sérgio Brazolin, Instituto de Pesquisas Tecnológicas do Estado de São Paulo \\ brazolin@ipt.br
}

\begin{abstract}
Resumo
Este artigo apresenta os resultados de uma pesquisa que estudou as potencialidades de aproveitamento da madeira proveniente da poda e supressão de árvores urbanas. Nela procurouse entender como o campo do design pode contribuir com o desenvolvimento da gestão sustentável em ambientes urbanos, apontando oportunidades promissoras observadas a partir do estudo de caso de indivíduos arbóreos da espécie invasora Leucaena leucocephala existentes no Campus Universitário Armando Sales de Oliveira. A pesquisa abrangeu: análise do sistema de poda e descarte de resíduos de árvores no local, necessidades e infraestrutura existentes junto aos cursos de design e arquitetura; estudo sobre sistemas de aproveitamento de madeira urbana e sobre as características da espécie objeto da investigação; testes, ensaios físicos e mecânicos; e experimentos aplicando as principais operações da marcenaria tradicional nos galhos coletados. Verificou-se que o material poderia ser utilizado em atividades acadêmicas, reduzindo seu descarte e suprindo parte da demanda local existente.
\end{abstract}

Palavras-chave: valorização de resíduos; arborização urbana; leucena; gestão ambiental.

\begin{abstract}
This paper presents the results of a research that studied the potential of using wood obtained from urban trees pruning and removal and tried to understand how the design field can contribute to the development of the sustainable management in urban environments, pointing promising opportunities observed through the case study of trees individuals from the invasive species Leucaena leucocephala, found in the University of Sao Paulos Armando Sales de Oliveira campus. The work implied an analysis of the pruning and disposal system of this kind of residue at the site, as well as the existing infrastructure used by the graduation courses in design and architecture; study on urban wood valuation systems and on the characteristics of the species under investigation; physical and mechanical tests and experiments with collected branches. It was found that the material could be used in academic activities, reducing its disposal and supplying part of the existing local demand.
\end{abstract}

Keywords: waste valuation; urban afforestation; leucena; environmental management 


\section{Introdução}

Os estudos sobre gestão ambiental e beneficiamento de resíduos, especialmente os arbóreos, são majoritariamente produzidos por profissionais da engenharia, biologia, administração e, em alguns casos, da arquitetura ou paisagismo. Embora o tópico do aproveitamento de resíduos, de modo geral, seja tratado por diversos autores da área do design, como Braungart e McDonough (2013) e Santos (2014), o tema do reuso da madeira de poda permanece, em nosso país, tratado apenas pelo campo das ciências florestais, como os relevantes trabalhos de Alves (2007), Meira (2013) e Martins (2013).

Este trabalho, além de procurar aproximar mais o design do assunto, relaciona-se com os princípios do Design para a Sustentabilidade e insere-se no âmbito dos "projetos para novos cenários que correspondam ao estilo de vida sustentável" (MANZINI e VEZZOLI, 1998), por articular-se com uma nova cultura de projeto que envolve a destinação de resíduos, num sistema circular ou cíclico. Simultaneamente, está alinhado com os objetivos da Universidade de São Paulo em relação à gestão responsável de seus campi; desde 1994 (LEME et al., 2012) programas como o USP Recicla são voltados especialmente para a minimização de resíduos e incentivam a construção de novos saberes na área, iniciativas sistêmicas e multidimensionais que contribuam para que a universidade seja uma referência em gestão sustentável (MELLUCCI et al., 2015).

\section{Objetivos e procedimentos metodológicos}

O objetivo inicial desta pesquisa foi compreender o estado da arte do aproveitamento dos resíduos de poda de árvores urbanas no Brasil e investigar a introdução desse tipo de resíduo no ciclo produtivo. O campus universitário Armando Sales de Oliveira (CUASO) da Universidade de São Paulo (USP) foi um modelo para este estudo, sendo sua flora a geradora de resíduos e a Seção Técnica de Ensaios, Modelos e Experimentações Construtivas (STMEEC) da Faculdade de Arquitetura e Urbanismo, a potencial consumidora.

Do ponto de vista metodológico, o ponto de partida do trabalho foi um levantamento bibliográfico sobre o tema. A partir das pesquisas iniciais e da interação com o Instituto de Biociências da USP, o foco do trabalho foi direcionado ao estudo da madeira da Leucaena leucocephala, espécie invasora com presença danosa no campus, incluindo a coleta de amostras de 12 indivíduos arbóreos, seu desdobro e secagem controlada, seguida da realização de testes e análises com o material, voltados às demandas da STMEEC, realizadas no Instituto de Pesquisas Tecnológicas (IPT) do Estado de São Paulo. Por fim, testes de trabalhabilidade e adequação às necessidades dos estudantes foram elaborados na própria STMEEC.

\section{Fundamentos teóricos}

\section{O destino da madeira de poda e a sustentabilidade}

Dada a grande demanda por madeira pelos setores da construção civil, fabricação de móveis e outros artefatos, produção de celulose e geração de energia, torna-se um desafio necessário - 
sobretudo nas grandes cidades (SOUSA, 2019) - pensar em alternativas de produção dessa matéria-prima que inibam o desmatamento das matas nativas. Nesse sentido, novos modelos de produção e consumo vêm sendo cunhados, como é o caso do cradle to cradle, que em português pode ser traduzido como "do berço ao berço", significando um sistema de produção em que o resíduo (output) de um processo é a matéria-prima (input) para outro, minimizando a geração de resíduos (BRAUNGART e MCDONOUGH, 2013).

Mesmo sem serem vendidos, materiais de beneficiamento podem ser reabsorvidos pelo ciclo de produção, havendo interesse dos participantes (partes interessadas) de um dado sistema. Visando valorizar o lenho proveniente da poda e remoção de árvores urbanas, posicionando-o na cadeia econômica, tomou-se como fundamentação teórica central deste trabalho a abordagem do design sistêmico para a sustentabilidade, focada no conceito de economia circular, ou no projeto "do berço ao berço". Tal arcabouço permite articular a pesquisa aqui apresentada com outras investigações científicas da universidade que estudam a viabilidade de implantação e as características de um sistema de beneficiamento da madeira proveniente da poda e remoção de árvores no campus universitário (output) que possibilite, entre outras aplicações, a produção de modelos e protótipos (input).

Entretanto, foram encontrados muito poucos dados sobre tais resíduos no país.

Não há estimativa da geração diária de resíduos de poda urbana para os municípios do Brasil, mas se sabe que a maioria deles é destinada a terrenos baldios, lixões ou utilizados como lenha. Em alguns casos são encaminhados para o serviço de compostagem. No entanto estas ações são isoladas e desarticuladas, nem sempre suficientes para dar uma destinação adequada a todos os resíduos da arborização. Além disso, não há investimentos na infraestrutura e na valorização desses resíduos, e nem mesmo um modelo logístico para a sua coleta, processamento e distribuição dos produtos. (MEIRA, 2013, p. 21)

A NBR 10.004 (ABNT, 2004) define "resíduos sólidos" como resíduos nos estados sólidos ou semissólidos resultantes de atividades industriais, domésticas, hospitalares, comerciais, agrícolas, de serviços e de varrição. Eles são segregado nas classes: I - perigoso; II - não perigoso (II A não inertes e II B - inertes). De acordo com o descrito, o resíduo aqui tratado encontra-se na Classe II A - não inertes, juntamente com outros como papel, papelão e resíduos domiciliares. Dessa forma todos esses materiais podem ser descartados sem seleção e levados a aterros sanitários.

A operação tem dimensões grandiosas - os gastos mensais da Prefeitura de São Paulo com poda de árvores em 2018 situavam-se em torno de 4,6 milhões de reais (SILVA e FLORA, 2019), e só no campus CUASO, no mesmo ano, 7.000 árvores foram podadas (PUSPC, 2018); trata-se de uma situação insustentável, contribuindo para a exaustão das áreas dos aterros pela difícil compactação, contaminando solos e lençóis freáticos e gerando gás metano, um dos principais causadores do efeito estufa (MARTINS, 2013). Foi reportado em 2015 o crescimento do número de aterros sanitários em 52\%, segundo a Companhia Ambiental do Estado de São Paulo CETESB, devido ao esgotamento das áreas em uso e à falta de novas áreas livres para aterros (TOMAZELA, 2016).

\section{Experiências existentes no país}




\section{O beneficiamento de resíduos de poda}

No Brasil, a documentação oficial sobre iniciativas públicas municipais de beneficiamento de madeira urbana é escassa, porém Adriana Nolasco (apud MEIRA, 2013, pg. 30), professora do Departamento de Ciências Florestais da Escola Superior de Agricultura Luiz de Queiroz da USP, afirma que, em 2010, 73 municípios no país realizavam algum tipo de uso do lenho proveniente do manejo da floresta urbana, sendo as principais finalidades, a geração de composto orgânico e a confecção de mata-burros e estacas. Algumas iniciativas municipais de uso mais criativo do material foram encontradas em notícias online e vídeos na plataforma de compartilhamento de conteúdo audiovisual Youtube (www.youtube.com.br), porém com poucas informações. Uma delas é a Serraria Ecológica de Guarulhos, que desde 2009 consta na Lei Ordinária 6593 do município. Ela utiliza a madeira das podas e remoções para construção de móveis para escolas e parques (PREFEITURA DE GUARULHOS, 2018). Outra iniciativa interessante foi a parceria da Subprefeitura da Lapa (São Paulo) com a empresa Inova, responsável pelos serviços de limpeza em algumas regiões do município, no âmbito do Programa "Feiras e Jardins Sustentáveis", para transformar resíduos orgânicos provenientes de feiras livres e da poda de árvores em cavacos, húmus ou MDF (CIDADE DE SÃO PAULO, 2015).

\section{Oferta e demanda de resíduos de madeira no Campus Universitário}

\section{O manejo dos resíduos arbóreos no Campus}

O manejo da arborização urbana é parte das atividades a cargo das prefeituras municipais no Brasil. No CUASO, que tem sua própria prefeitura, o Serviço Técnico de Áreas Verdes da Cidade Universitária gerencia os trabalhos de manejo, realizados por empresas terceirizadas contratadas através de licitação. Segundo o engenheiro agrônomo Leonardo Augusto Verhalen responsável pelo setor, em entrevista concedida aos autores deste artigo, o Manual Técnico de Podas de Árvore da cidade de São Paulo é utilizado como guia para os procedimentos de poda no campus, sendo respeitada a Lei 10.365/1987, que disciplina o corte e a poda de vegetação de porte arbóreo no município.

O destino do resíduo é dado pela própria empresa terceirizada ou por contrato de caçambas, sem classificação dos resíduos. No caso das caçambas, os resíduos são levados para a empresa Made Vila, em Guarulhos, onde são usados para geração de energia; quando descartados pelas empresas de manutenção de áreas verdes contratadas, o material é levado para compostagem.

\section{Requisitos da madeira para uso na Seção Técnica}

A madeira é o material que apresenta maiores possibilidades de utilização pelos estudantes de arquitetura e design na STMEEC; a combinação de suas propriedades permite inúmeras aplicações. As aplicações mais recorrentes, finalidades e formas de emprego do material são:

- Maquetes - confeccionadas para simular a aparência do projeto em escala reduzida. A madeira empregada nas maquetes varia entre chapas de MDF (Medium Density Fiberboard) de $3 \mathrm{~mm}$ a $20 \mathrm{~mm}$ e sarrafos de madeira maciça de $5 \mathrm{~mm}$ x $5 \mathrm{~mm}$. 
- Moldes e contramoldes - usados para a confecção de produtos em compensado de madeira moldado ou em resina polimérica, devem ser confeccionados preferencialmente em madeira maciça. Entretanto, com a dificuldade de acesso ao material, em geral têm sido feitos a partir de chapas de MDF coladas umas sobre as outras, para a geração de uma peça volumosa, usinada na máquina CNC (comando numérico computadorizado).

- Protótipos - modelos em escala natural (1:1), construídos com material igual ou semelhante ao especificado no projeto (LIMA, 2006). Alunos do curso de design realizam protótipos de mobiliário ao longo do curso comprando, eles mesmos, a madeira maciça necessária.

A partir da caracterização desta demanda, foram definidos os requisitos técnicos (Tabela 1) a serem atendidos em cada situação, com base no estudo de autores do campo da metodologia do processo de design (BONSIEPE, 1978) e da seleção de materiais para designers (LIMA, 2006; ASHBY e JOHNSON, 2011):

\begin{tabular}{|l|l|l|}
\hline Produto & \multicolumn{1}{|c|}{ Requisitos técnicos da madeira } & Madeira comumente utilizada \\
\hline Maquete & $\begin{array}{l}\text { Resistência baixa, dureza baixa a média, } \\
\text { bom acabamento. }\end{array}$ & MDF, bambu, madeira de balsa. \\
\hline $\begin{array}{l}\text { Molde e } \\
\text { contramolde }\end{array}$ & $\begin{array}{l}\text { Resistência baixa a média, dureza baixa } \\
\text { a média, bom acabamento. }\end{array}$ & Caixeta, MDF, compensado. \\
\hline Protótipo & $\begin{array}{l}\text { Resistência média a alta, dureza média a a } \\
\text { alta, bom acabamento. }\end{array}$ & $\begin{array}{l}\text { Madeiras como pinus, cedro, } \\
\text { cedrinho, tauari, cumarú e } \\
\text { eucalipto; MDF, compensado. }\end{array}$ \\
\hline
\end{tabular}

Tabela 1: Requisitos técnicos da madeira a ser utilizada pelos alunos na Seção Técnica.

\section{A espécie escolhida: Leucaena leucocephala}

Diante da grande diversidade de espécies arbóreas encontradas no campus universitário e da carência de estudos mais aprofundados sobre as potencialidades da madeira de cada uma delas sobretudo em se tratando dos galhos - entendeu-se que seria mais adequado focar em uma única espécie, permitindo um estudo em profundidade e a realização de mais testes, dentro do período de vigência da pesquisa. Para escolha da espécie, foram considerados:

- Volume de resíduos gerado - a espécie escolhida deveria ser uma geradora de material em potencial, reduzindo seu descarte.

- Potencial de adequação aos requisitos técnicos definidos - mesmo não existindo informações aprofundadas sobre a espécie escolhida, a bibliografia deveria indicar uma grande probabilidade de a madeira suprir a demanda. 
- Facilidade de coleta de amostras - seria necessário optar por uma espécie da qual se pudesse colher amostras com certa facilidade, devido ao prazo e recursos disponíveis.

Em interação com o Prof. Dr. Gregório Ceccantini do Instituto de Biociências (IB), foi acordado que a espécie Leucaena leucocephala (imagens 1 e 2) seria apropriada, uma vez que sua presença no Campus vinha gerando preocupação por seu comportamento como espécie invasora, reproduzindo-se com velocidade e inibindo a flora natural local. O Global Invasive Species Database (Base de Dados Global de Espécies Invasoras) do Invasive Species Specialist Group (Grupo Especialista em Espécies Invasoras) a descreve como uma planta:

...de rápido crescimento, fixadora de nitrogênio, usada para produção de forragem, reflorestamento e proteção contra o vento, (...) que foi introduzida em muitas localidades por suas qualidades, mas tem se tornado uma invasora agressiva em zonas tropicais e subtropicais e é listada como uma das 100 espécies invasoras mais perigosas. Essa árvore sem espinhos pode formar uma comunidade densa e monoespecífica que é difícil de ser erradicada uma vez estabelecida. Ela torna áreas extensas inutilizáveis e inacessíveis, ameaçando plantas nativas. (ISSG, s.d.)

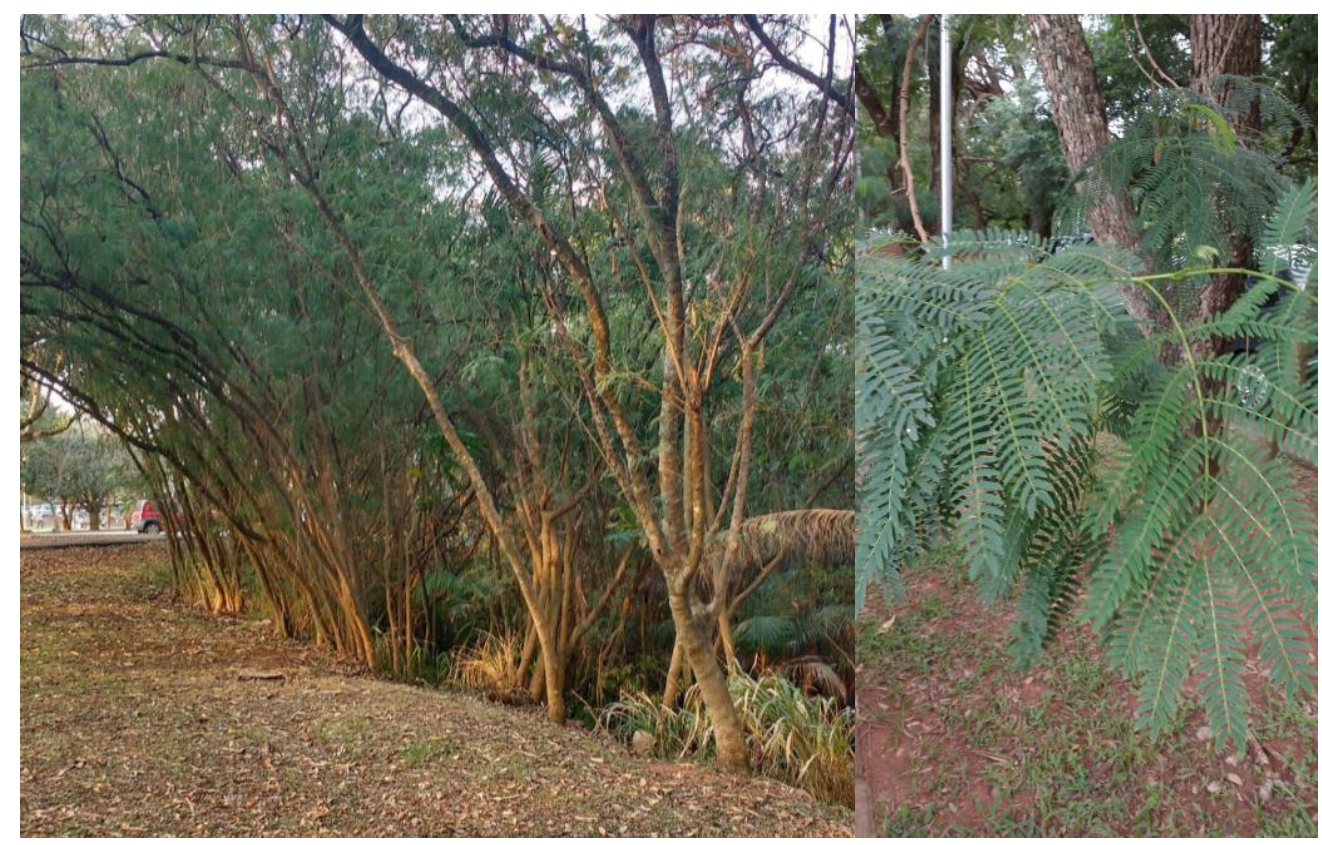

Imagens 1 e 2: Leucena na Cidade Universitária. Fonte: Acervo pessoal dos autores.

A leucena foi introduzida no Brasil por volta de 1940 em regiões semiáridas com o intuito de reflorestar zonas desmatadas, em especial encostas (EMBRAPA, 2017). Na época era conhecida como "planta milagrosa" que crescia rápido, sem precisar de muita água. Entretanto, inibindo as plantas nativas, tornou-se um problema para a gestão de florestas locais. Sua erradicação não é simples: ela tem grande capacidade regenerativa e suas sementes resistem no solo por longos períodos. O problema tem sido reportado em Aracaju, Fernando de Noronha, Niterói, Campinas, Ribeirão Preto e Piracicaba, entre outros locais do país. No campus universitário, a leucena encontra-se em diversos pontos; na região próxima ao Instituto de Biomedicina (imagem 3) vem se proliferando e inibindo as demais árvores da região de mata que separa a Cidade Universitária do bairro Vila Indiana. 


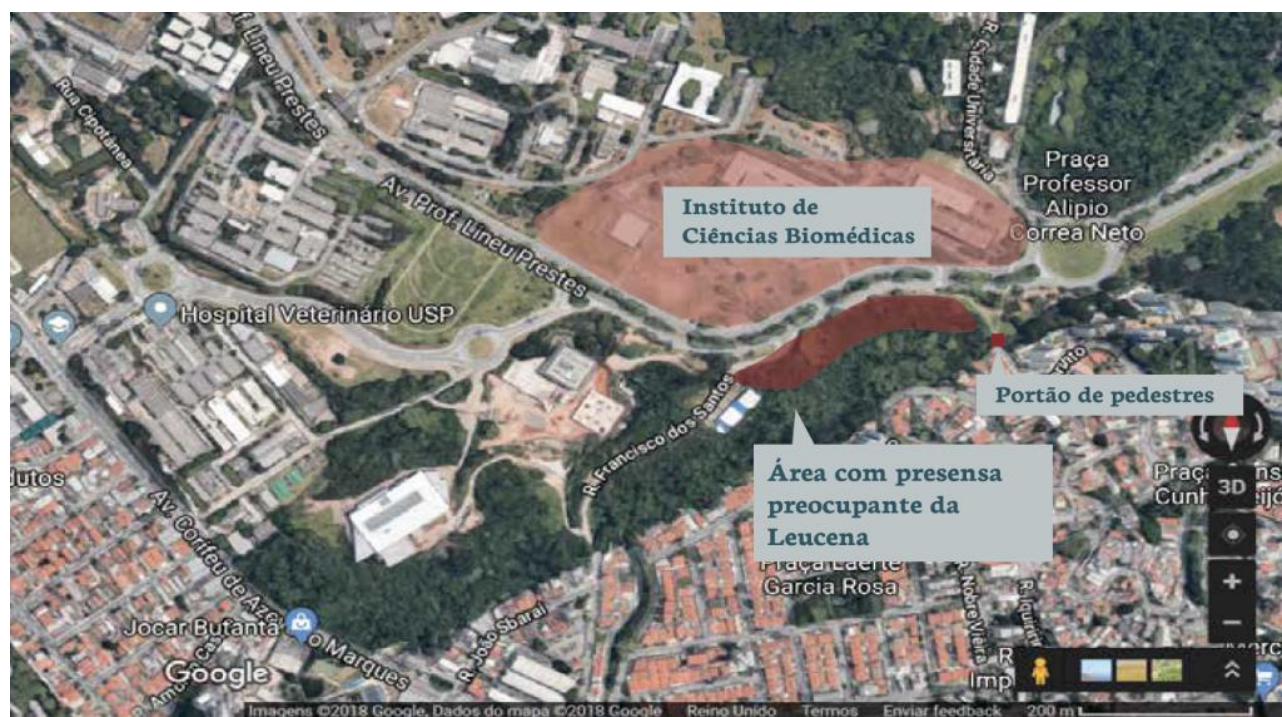

Imagem 3: Área de maior infestação e coleta das amostras na Cidade Universitária. Fonte: Acervo pessoal dos autores.

As tabelas 2 e 3 mostram características biológicas e tecnológicas da árvore de leucena, sendo possível observar algumas informações conflitantes, provavelmente pela diversidade das fontes, que diferem tanto em data da publicação (de 1980 até 2017) quanto nas localidades dos estudos realizados (África, Oriente Médio, América Central e América Latina).

\begin{tabular}{|l|l|}
\hline Aspecto & Características biológicas \\
\hline Nome científico & $\begin{array}{l}\text { Leucaena leucocephala (1) } \\
\text { 'leucocephala' vem de 'leu', que significa branco, e 'cephala', significa } \\
\text { cabeça, fazendo referência às flores. (6) }\end{array}$ \\
\hline $\begin{array}{l}\text { Nome popular } \\
\text { (port., esp., ing.) }\end{array}$ & $\begin{array}{l}\text { Leucena (1)(2) (Português); Lead Tree (7) / Wild Tamarind (7) / Jumpy-bean } \\
\text { (6) (Inglês); }\end{array}$ \\
\hline Sinônimos & $\begin{array}{l}\text { Leucaena glauca (Moench.) Benth.; } \\
\text { Mimosa glauca L. (1) }\end{array}$ \\
\hline Família & Mimosaceae (Leguminosae - Mimosoideae) (1) \\
\hline Origem & $\begin{array}{l}\text { América Central (1)(2) } \\
\text { Viferem em porte e produção de biomassa foliar, sendo agrupadas em três } \\
\text { tipos: "Havaiano", "Salvador" e "Peru". Em geral, as variedades são } \\
\text { conhecidas por números precedidos da letra "K". (1) Existem 3 subespécies } \\
\text { reconhecidas: ssp. leucocephala, ssp. glabrata (Rose) S. Zárate, e ssp. } \\
\text { ixtahuacana C. E. Hughes. (6) }\end{array}$ \\
\hline
\end{tabular}




\begin{tabular}{|l|l|}
\hline $\begin{array}{l}\text { Descrição } \\
\text { botânica }\end{array}$ & $\begin{array}{l}\text { Das } 22 \text { espécies do gênero, a Leucaena leucocephala é a mais difundida e de } \\
\text { maior distribuição geográfica. É uma planta arbóreo arbustiva, com altura de } \\
\text { até } 20 \mathrm{~m} \text { e diâmetro à altura do peito (DAP) de até } 30 \mathrm{~cm} \text {. Possui folhas } \\
\text { bipinadas de } 15 \text { a } 20 \mathrm{~cm} \text { de comprimento, com } 4 \text { a } 10 \text { pares de pinas, cada } \\
\text { uma com } 5 \text { a } 20 \text { pares de folíolos; folíolos com } 7 \text { a } 15 \mathrm{~mm} \text { de comprimento e } \\
3 \text { a } 4 \mathrm{~mm} \text { de largura. } \\
\text { Numerosas flores brancas se agrupam em capítulo globular de } 1,5 \text { a } 3 \mathrm{~cm} \text { de } \\
\text { diâmetro. Os frutos são vagens planas, de } 12 \text { a } 18 \mathrm{~cm} \text { de comprimento e } 1,5 \mathrm{a} \\
2,0 \text { cm de largura, contendo } 15 \text { a } 30 \text { sementes elípticas, achatadas, brilhantes, } \\
\text { de cor marrom, com } 6 \text { a } 8 \text { mm de comprimento e } 3 \text { a } 4 \text { mm de largura. (1) }\end{array}$ \\
\hline Biologia & $\begin{array}{l}\text { As flores são autoférteis e a maioria das sementes resulta de autopolinização. } \\
\text { Floração e frutificação ocorrem ao longo do ano, desde que haja umidade. (6) }\end{array}$ \\
\hline Solos & $\begin{array}{l}\text { Tolera parcialmente solos salinos, desenvolvendo-se bem em solos drenados } \\
\text { com pH entre 5,5 e 8,5. Não se desenvolve bem em solos com altos teores de } \\
\text { alumínio (1). É intolerante a solos com baixo pH, baixo fósforo, cálcio, alta } \\
\text { salinidade e excesso de água, podendo morrer. (6) }\end{array}$ \\
\hline
\end{tabular}

Tabela 2: Características biológicas da espécie Leucaena leucocephala. Fontes consultadas: (1) Drumond e Ribaski (2010); (2) Otsyina e Dzowela (s.d.); (3) Hindi (2017); (4) Pottinger e Hughes (1994) apud Otsyina e Dzowela (s.d.); (5) NAS (1980) apud Otsyina e Dzowela (s.d.); (6) Orwa et al. (2010); (7) Conrad (2007).

\begin{tabular}{|c|c|c|}
\hline Aspecto & Características tecnológicas & Observações \\
\hline $\begin{array}{l}\text { Densidade } \\
\text { básica }\end{array}$ & $\begin{array}{l}620 \mathrm{~kg} / \mathrm{m}^{3}(1) ; 597 \mathrm{~kg} / \mathrm{m}^{3}(3) ; 670- \\
730 \mathrm{~kg} / \mathrm{m}^{3}(5) ; 450-550 \mathrm{~kg} / \mathrm{m}^{3}(6)\end{array}$ & $\begin{array}{l}\text { Densidade média e secagem sem } \\
\text { rachaduras; resistente, textura } \\
\text { média, veios próximos. Facilmente } \\
\text { trabalhável para vários fins na } \\
\text { carpintaria. (6) }\end{array}$ \\
\hline $\begin{array}{l}\text { Poder } \\
\text { calorífico }\end{array}$ & $\begin{array}{l}4.200 \text { a } 4.600 \text { Kcal } / \mathrm{kg}-1 \quad(1) ; 4600 \\
\mathrm{Kcal} / \mathrm{kg}-1(6)\end{array}$ & \\
\hline Peso específico & 0,55 e $0,70 \mathrm{~g} / \mathrm{cm}^{3}(1)$ & \\
\hline Usos populares & $\begin{array}{l}\text { Enriquecimento, melhoria de solos } \\
(1)(2)(6) ; \text { Sombra para cultivos } \\
(1)(2)(6) ; \text { Controle de erosão (1)(6); } \\
\text { Alimento in natura (México)(7); } \\
\text { Alimento fermentado (Indonésia) } \\
(6) \text {; Substituto do café(6); Lenha ou } \\
\text { carvão (1)(2)(4); Madeira para } \\
\text { cercados (2)(4)(6); Alimento para } \\
\text { gado (1)(2)(6); Papel ou material de } \\
\text { embalagens (6); Sementes secas } \\
\text { como enfeites (6). }\end{array}$ & $\begin{array}{l}\text { Postes para escorar plantações. Uso } \\
\text { limitado pela baixa durabilidade e } \\
\text { resistência a cupins e outros xilófagos } \\
\text { (6). }\end{array}$ \\
\hline
\end{tabular}




\begin{tabular}{|c|c|c|}
\hline $\begin{array}{l}\text { Usos potenciais } \\
\text { (ainda pouco } \\
\text { explorados) }\end{array}$ & $\begin{array}{l}\text { Papel e painéis de partícula } \\
(1)(3)(4) \text {; Artesanato (4); Tacos para } \\
\text { piso (4)(6); Mobiliário (4). }\end{array}$ & $\begin{array}{l}\text { O uso limitado como madeira } \\
\text { serrada por suas pequenas } \\
\text { dimensões }(<30 \mathrm{~cm} \text { de diâmetro), e } \\
\text { ramificação, reduzindo as seções de } \\
\text { tronco limpo disponível; madeira } \\
\text { com muitos nós e alta porcentagem } \\
\text { de lenho juvenil (6). Pigmentos } \\
\text { vermelhos, marrons e pretos } \\
\text { extraídos da vagem, folha e casca (6). }\end{array}$ \\
\hline
\end{tabular}

Tabela 3: Características mecânicas da madeira da espécie Leucaena leucocephala. Fontes consultadas: (1) Drumond e Ribaski (2010); (2) Otsyina e Dzowela (s.d.); (3) Hindi (2017); (4) Pottingere e Hughes (1994) apud Otsyina e Dzowela (s.d.); (5) NAS (1980) apud Otsyina e Dzowela (s.d.); (6) Orwa et al. (2010); (7) Conrad (2007).

\section{Coleta, preparação de amostras e realização de ensaios}

Para conhecer as propriedades da madeira de leucena crescida no campus universitário, foi realizada uma coleta de amostras de galhos no local, com o suporte técnico-operacional da Xiloteca do IB-USP, reunindo galhos de 12 indivíduos diferentes, com $70 \mathrm{~cm}$ de comprimento e 10 a $12 \mathrm{~cm}$ de diâmetro.

A transformação do galho em uma amostra ou peça padronizada pronta para ser utilizada na produção de um objeto, componente ou elemento construtivo, passa por processos básicos como: desdobro, secagem e eventual aplicação de produto protetor, não necessariamente nesta ordem. Neste projeto, o desdobro foi feito na STMEEC e a secagem controlada, na sala de climatização do IPT , com $20 \pm 3^{\circ} \mathrm{C}$ e $65 \pm 5 \%$ de umidade relativa.

A secagem durou 62 dias. Para controle do teor de umidade, foram realizadas pesagens semanais das amostras, com valor documentado para comparação. Quando a variação de peso das amostras tornou-se menor que $4 \%$ em 24 horas, elas foram consideradas secas e sua umidade em equilíbrio com o ambiente. Então foram realizados os seguintes ensaios: flexão estática, dureza e densidade aparente (ABNT - NBR 7190:1997).

\section{Resultados dos ensaios}

As Tabelas 4 e 5 apresentam os resultados dos ensaios realizados. Conforme mostra a Tabela 4, com densidade média/alta e resistência à flexão, a madeira da leucena possui características favoráveis para produtos resistentes à aplicação de peso como no mobiliário. Segundo o catálogo de madeiras online do IPT - Instituto de Pesquisas Tecnológicas de São Paulo, outras madeiras com propriedades mecânicas semelhantes, aplicadas na fabricação de móveis de alta qualidade são: tauari (Couratari spp.) com densidade de massa de $610 \mathrm{~kg} / \mathrm{m}^{3}$, resistência à flexão de 88,8 MPa e módulo de elasticidade à flexão de $10591 \mathrm{MPa}$; angelim-pedra (Hymenolobium petraeum Ducke) com densidade de massa de $710 \mathrm{~kg} / \mathrm{m}^{3}$, resistência à flexão de 109,3 MPa e módulo de elasticidade à flexão de $11572 \mathrm{MPa}$. 


\begin{tabular}{|l|l|l|l|l|}
\hline Valor & $\begin{array}{l}\text { Teor de } \\
\text { Umidade de } \\
\text { Equilíbrio }(\%)\end{array}$ & $\begin{array}{l}\text { Densidade de } \\
\text { massa aparente } \\
\mathbf{a} \mathbf{1 2 \%}\left(\mathbf{k g} / \mathbf{m}^{3}\right)\end{array}$ & $\begin{array}{l}\text { Resistência } \\
\text { à flexão } \\
(\mathbf{M P a})\end{array}$ & $\begin{array}{l}\text { Módulo de } \\
\text { elasticidade à } \\
\text { flexão (MPa) }\end{array}$ \\
\hline Média & 16,4 & 735 & 97 & 12517 \\
\hline Desvio padrão & 3,3 & 73 & 25 & 1872 \\
\hline
\end{tabular}

Tabela 4: Ensaios realizados: umidade, densidade, resistência à flexão e módulo de elasticidade.

\begin{tabular}{|l|l|l|l|}
\hline Valor & Axial & Radial & Tangencial \\
\hline Média & 72 & 67 & 69 \\
\hline Desvio padrão & 11 & 15 & 11 \\
\hline
\end{tabular}

Tabela 5: Ensaios realizados: dureza Janka (Mpa).

Por sua vez, os resultados apresentados na Tabela 5 revelaram que, com uma dureza média, a madeira da leucena pode ser mais difícil de ser perfurada e seu corte deve exigir menor velocidade e mais atenção. Também significa que seu acabamento com lixa pode ser mais trabalhoso, mas apresenta bons resultados. Em relação a esta propriedade e suas consequências quanto à trabalhabilidade, de acordo com o catálogo online do IPT, o material compara-se a madeiras como o ipê (Tabebuia spp.) e a cabreúva-vermelha (Myroxylon balsamum), ambos também utilizados no mobiliário.

\section{Painel de trabalhabilidade}

Complementando os ensaios, investigou-se a trabalhabilidade, ou resposta da madeira de leucena, às operações mais comuns utilizadas pelos alunos da FAU e funcionários da STMEEC na construção de modelos, maquetes e protótipos. O resultado foi apresentado em um painel visual e tátil (imagens 4,5 e 6 ).

Na marcenaria, o sentido das fibras da madeira é de extrema relevância e determina se uma operação será bem sucedida, já que o material responde de modo diferente, dependendo do posicionamento. Assim, para estes testes, as amostras foram reunidas em dois grandes grupos: seção ou corte longitudinal (no sentido das fibras); e transversal, ou de topo (contra o sentido das fibras). Foram realizadas nove operações, classificadas em três categorias: União - parafuso, cavilha e prego; Subtração - lixar, cortar e furar; Acabamento - seladora, cera e tinta guache. Cada operação foi realizada em seis amostras de tamanho 50x50x40 mm (três no sentido da fibra e três contra o sentido da fibra), sendo avaliadas a partir do resultado conjunto.

A configuração final do painel adquiriu o formato de uma caixa composta por três bandejas empilhadas, contendo as amostras trabalhadas em uma das categorias mencionadas, com as operações indicadas e um breve comentário sobre o resultado. Algumas operações foram bem sucedidas: a leucena apresentou ótimo acabamento quando cortada e lixada, e ainda melhor com 
a aplicação de seladora. Entretanto, suas longas fibras apresentaram tendência a rachar com a pressão, exigindo muita atenção nas operações de união ou subtração de material com fresas ou brocas. Assim, concluiu-se que a madeira da leucena poderia ser aplicada nos exercícios didáticos da Seção Técnica, principalmente como material para protótipos pela sua resistência e bom acabamento; por outro lado, não seria indicada para molde e contramolde, pela dificuldade de usinagem.

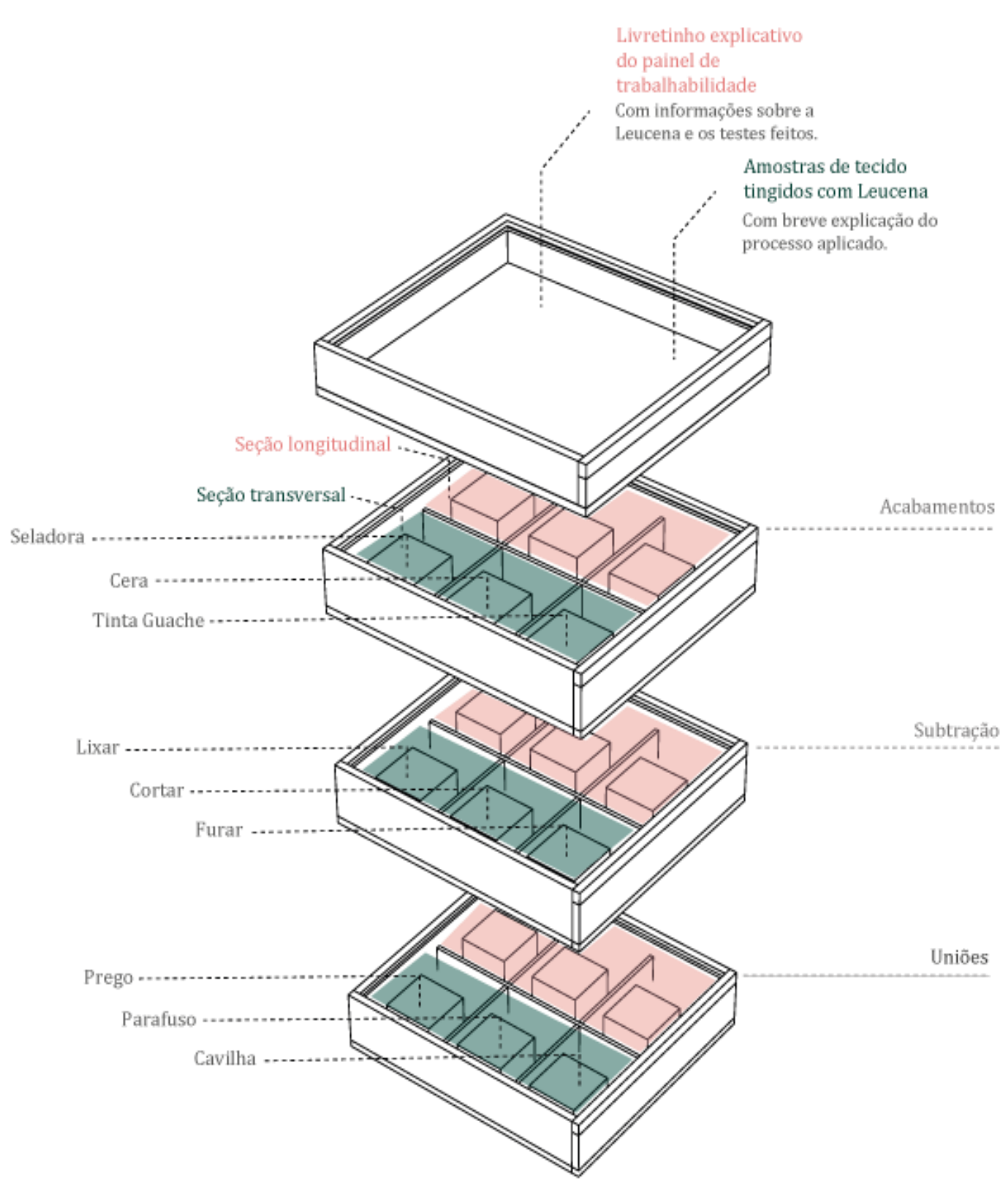

Imagem 4: Esquema ilustrativo do Painel de Trabalhabilidade. 

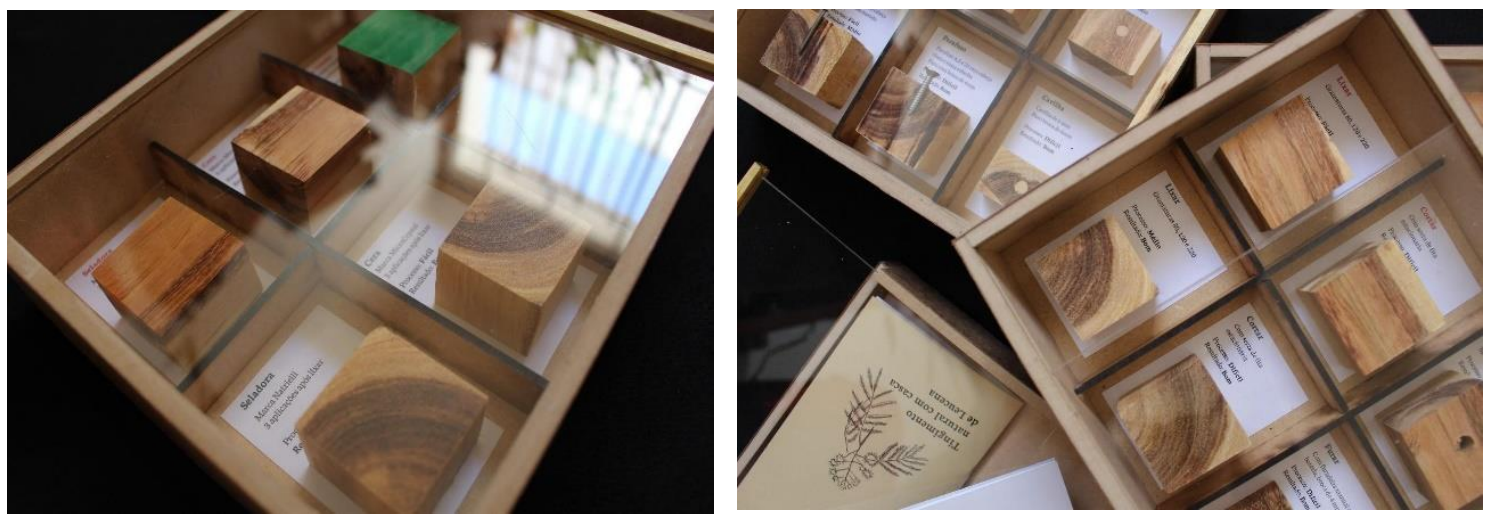

Imagens 5 e 6: fotografias do Painel de Trabalhabilidade finalizado. Fonte: Acervo pessoal dos autores.

\section{Resultados e conclusões}

Esta pesquisa ressaltou que a poda ou supressão da leucena gera grande quantidade de resíduos. Considerando sua proliferação e natureza invasora, que tem motivado esforços por sua erradicação, estudos que apontem novas perspectivas de aproveitamento de sua madeira podem ser significativamente relevantes. Como verificado, a leucena pode ser utilizada por estudantes de design e arquitetura, com bons resultados. Sua grande resistência, densidade média/alta, boa trabalhabilidade e aparência extraordinária - com desenhos e veios marcados -, combinados com o tamanho reduzido das peças obtidas com sua poda, demosntram seu potencial para a confecção de pequenos objetos de madeira (POMs) e mobiliário de pequeno porte, onde a aparência tem grande importância. Sua aplicabilidade na construção de modelos e protótipos, se mostra promissora; entretanto, não se adequa à produção de moldes, sobretudo usinados em router CNC.

Embora a investigação aqui apresentada tenha

caráter específico, pode contribuir com a destinação dos resíduos arbóreos do campus da USP, de forma inovadora e criativa. A partir dela percebeu-se que, reconhecendo que as árvores urbanas podem desempenhar outras funções além de prover sombra e frescor, os habitantes das cidades podem renovar sua relação com elas, repensando o descarte, valorizando a madeira, minimizando o consumo, poupando florestas e contribuindo para viabilizar novos cenários de estilo de vida.

\section{Referências}

ALVES, B. L. G. Paisagismo Urbano: Gestão e Subtração de Volumes nos Aterros Sanitários. Dissertação de mestrado. Rio de Janeiro: Universidade do Estado do Rio de Janeiro - UERJ, 2007.

ASHBY, M.; JOHNSON, K. Materiais e design: arte e ciência da seleção de materiais no design de produto. 2 ed. Rio de Janeiro: Campus-Elsevier, 2011.

ASSOCIAÇÃO Brasileira de Normas Técnicas. NBR 10.004: Resíduos sólidos classificação. Rio de Janeiro: ABNT, 2004. 
ASSOCIAÇÃO Brasileira de Normas Técnicas. NBR 7190 - Projeto de estruturas de madeira. Rio de Janeiro: ABNT, 1997.

BONSIEPE, G. 1978. Teoría y práctica del diseño industrial. Elementos para uma manualística crítica. Barcelona: Gustavo Gili, 1978.

BRAUNGART, M. e MCDONOUGH, W. Cradle to cradle: criar e reciclar ilimitadamente. São Paulo: Gustavo Gili, 2013.

CIDADE DE SÃO PAULO. Subprefeitura Lapa. Prefeitura lança pátio-piloto do programa Feiras e Jardins Sustentáveis na Lapa. Acesso à informação.

Disponível

em:

https://www.prefeitura.sp.gov.br/cidade/secretarias/subprefeituras/lapa/noticias/?p=6 2967> Acesso em: 27 de março de 2020.

CONRAD, J. Wild tamarind/ Guaje. In: Naturalist Newsletter. March, 3, 2007. Disponível em: <http://www.backyardnature.net/q/guaje.htm> Acesso em: 27 de março de 2020.

DRUMOND, M. A.; RIBASKI J. Leucena (Leucaena leucocephala): leguminosa de uso múltiplo para o semiárido brasileiro. In: Comunicado Técnico, n. 142. Embrapa Semiárido. Petrolina, PE: dezembro, 2010. ISSN 1808-9984.

EMBRAPA. A "milagrosa" Leucena pode ser uma praga. 2017. Disponível em: < https://www.youtube.com/watch?v=AczvqfirMRM> Acesso em: 27 de março de 2020 .

HINDI, S. Some Promising Hardwoods for Cellulose Production: I. Chemical and Anatomical Features. Nanoscience and Nanotechnology Research, v. 4, n. 3, 86-97, 2017.

ISSG - Invasive Species Specialist Group. Leucaena leucocephala. In: Global Invasive Species Database. Disponível em: <http://www.iucngisd.org/gisd/species.php?sc=23> Acesso em: 27 de março de 2020.

LEME, P. S.; MARTINS, J.L.G.; BRANDÃO, D. Guia prático para minimização e gerenciamento de resíduos. São Carlos/SP: USP São Carlos, 2012.

LIMA, M. A. M. Introdução aos materiais e processos para designers. Rio de Janeiro: Ciência Moderna, 2006.

MANZINI, E.; VEZZOLI, C. O desenvolvimento de produtos sustentáveis: requisitos ambientais dos produtos. São Paulo: EdUSP, 1998.

MARTINS, C. H. O aproveitamento de madeiras das podas da arborização viária de Maringá/PR. In: Revista Verde, Mossoró, v. 8, n. 2, p. 257 - 267, 2013.

MEIRA, A. M. de. Gestão de resíduos da arborização urbana. Tese de doutorado. Piracicaba: Universidade de São Paulo Escola Superior de Agricultura "Luiz de Queiroz", 2013. 
MELLUCCI, A. M., CICCOTTI, L., LIMA, E. T., MARINHO, C. E., DIAS, S. L. F. G., GÜNTHER, W. M. R., MERCEDES, S. S., AMBRIZZI, T. e PHILIPPI JUNIOR, A. Gestão integrada de resíduos no Campus USP da capital - Programa Campus sustentável Universidade de São Paulo, Brasil. In: Elaus 2015 - II Encontro Latino Americano da Universidades Sustentáveis. Porto Alegre/RS: Escola de Administração/UFRGS. 29-30/10/2015, 1-13.

ORWA, C.; MUTUA, A.; KINDT, R.; JAMNADASS, R.; SIMONS, A. Agroforestree Database: a tree reference and selection guide version 4.0. 2010. Disponível em: < http://www.worldagroforestry.org/publication/agroforestreedatabase-tree-reference-and-selection-guide-version-40> Acesso em 27 de março de 2020.

OTSYNA R.; DZOWELA B. Importance of Leucaena in Africa. In: FAO.org. Disponível em: < http://www.fao.org/docrep/008/v5020e/V5020E04.htm\#03.1.1> Acesso em: 27 de março de 2020.

PREFEITURA DE GUARULHOS. Serraria Ecológica. 2018. Disponível em: $<$ https://www.youtube.com/watch?v=pXYziWurahA\&feature=youtu.be > Acesso em: 27 de março de 2020.

PUSPC - USP Prefeitura Campus da Capital. Poda de Árvores nas Áreas Comuns do Campus. 05/09/2018. Disponível em: <https://puspc.usp.br/2018/09/05/poda-dearvores-nas-areas-comuns-campus-2/> Acesso em: 24 de março de 2020.

SANTOS, M. C. L. dos. Design, resíduo e dignidade. São Paulo: Olhares, 2014.

SILVA, E. e FLORA, K. Subprefeituras de SP gastam R\$ 4,6 milhões por mês com podas de árvores. In: 32XSP. 11/03/2019. Disponível em: < https://32xsp.org.br/2019/03/11/subprefeituras-de-sp-gastam-4-milhoes-pormes-com-podas-de-arvores/> Acesso em: 24 de março de 2020.

SOUSA, C. M. de. Waste valuing from urban wood management through design. Ideas from the case of San Paulo. In: Agathón International Journal of Architecture, Art and Design. $\quad$ v. 6. 2019. (pp. 228-239). Disponível em: <https://www.agathon.it/agathon/article/view/172> Acesso em: 23 de abril de 2020.

TOMAZELA, J. M. Aterros sanitários inadequados crescem 52\% em São Paulo. In: Jornal Estado de São Paulo, 11/05/2016. Disponível em: <https://saopaulo.estadao.com.br/noticias/geral,aterros-sanitarios-inadequados-crescem-52-emsao-paulo,10000050509> Acesso em: 27 de março de 2020.

\section{Sobre os autores}

Clara de Souza Bartholomeu é estudante de Design da FAU-USP e atualmente cursa o duplo diploma com a Laurea Magistrale em Design Integrado de Produtos no Politecnico di Milano. bartholomeuclara@gmail.com 
Cyntia Santos Malaguti de Sousa é designer formada na ESDI/UERJ e doutora em arquitetura e urbanismo pela FAU/USP. É professora-pesquisadora dos cursos de graduação e pósgraduação em design da FAU/USP. Especializada em design para sustentabilidade e gestão do design, desenvolve pesquisas abrangendo temas como economia circular, cultura material, estudos de futuro e matérias-primas para design, incluindo resíduos da arborização urbana. cyntiamalaguti@usp.br

Sergio Brazolin é biólogo, formado no Instituto de Biociências da USP e doutor em recursos florestais pela ESALQ/USP. Atua no Laboratório de Árvores, Madeiras e Móveis do Instituto de Pesquisas Tecnológicas do Estado de São Paulo, com biodeterioração, proteção da madeira e silvicultura urbana. Participa no planejamento da arborização urbana e biomecânica de árvores, auxiliando o poder público em políticas e programas de manejo preventivo.

brazolin@ipt.br 